\title{
Communicating Employability: the Role of Communicative Competence for Zimbabwean Highly Skilled Migrants in the UK
}

\author{
Roda Madziva $\cdot$ Simon McGrath $•$ Juliet Thondhlana
}

(C) Springer Science+Business Media Dordrecht 2014

\begin{abstract}
Skilled migration is an increasingly important topic for both policy and research internationally. OECD governments in particular are wrestling with tensions between their desire to use skilled migration to be on the winning side in the 'global war for talent' and their pandering to and/or attempts to outflank rising xenophobia. One aspect that has received relatively little attention is skilled migration from the African Commonwealth to the UK, a situation in which skilled migrants have relatively high levels of linguistic capital in the language of the host country. We focus here on the case of Zimbabwe. In spite of its popular image as a failed state, Zimbabwe has an exceptionally strong educational tradition and high levels of literacy and fluency in English. Drawing on 20 in-depth interviews of Zimbabwean highly skilled migrants, we explore the specific ways in which the communicative competences of these migrants with high formal levels of English operate in complex ways to shape their employability strategies and outcomes. We offer two main findings: first, that a dichotomy exists between their high level formal linguistic competence and their ability to communicate in less formal interactions, which challenges their employability, at least when they first move to the UK; and second, that they also lack, at least initially, the competence to narrativise their employability in ways that are culturally appropriate in England. Thus, to realise the full potential of their high levels of human capital, they need to learn how to communicate competently in a very different social and occupational milieu. Some have achieved this, but others continue to struggle.
\end{abstract}

Keywords Highly skilled migrants $\cdot$ Employability · Communicative competence · Human capital · Zimbabwe

\section{R. Madziva}

School of Sociology, University of Nottingham, University Park, Nottingham NG7 2RD, UK

S. McGrath · J. Thondhlana $(\bowtie)$

School of Education, University of Nottingham, Jubilee Campus, Wollaton Road, Nottingham NG8 1BB, UK

e-mail: juliet.thondhlana@nottingham.ac.uk 


\section{Introduction}

Although the whole point of allowing and encouraging skilled migration from the point of view of host countries is to introduce higher levels of human capital into their workforces, there has been a growing literature about the challenges faced by such migrants in accessing and performing effectively within the job market (e.g. Henderson et al. 2001; Schellekens 2001; Benson-Rea and Rawlinson 2003). These employability issues (cf. Hillage and Pollard 1998; classic definition) are seen as arising from a number of factors. These include the effects of immigration legislation, the playing out of racism and xenophobia, questions (legitimate or otherwise) about the comparability of their qualifications and work experience, and inadequate proficiency in the host language.

The issue of language has received considerable attention in the literature, with the focus predominantly being on the issue of inadequate proficiency (Grenier and Vaillancourt 1983; Chiswick et al. 2006; Chiswick and Miller 2007; Van Tubergen and Kalmijn 2009). Yet, for many migrants to ex-colonial powers (and from the Commonwealth to the other Anglophone developed countries), such language issues are less stark. For example, studies of African migration to Australia, New Zealand and the USA found highly skilled Anglophone African migrants to have 'strong English skills' but observed that this was not always matched with their employability. (Hawthorne and Burrell 1997; Capps et al. 2011; Negash 2011; Canagarajah 2013). We define a highly skilled migrant as one possessing at least a university degree (Harvey 2008). Zimbabwean graduates, for instance, will have encountered English in the classroom from the earliest days of their education and will have had most of their formal education in English for more than a decade of their lives. They will have passed an English ' $O$ ' Level that requires high levels of competence in areas such as grammar and so can justifiably be described as having a high proficiency level in formal English. However, as we will explore in this paper, such a focus on formal linguistic competence is only part of the story. In addition, attention needs to be paid to communicative and other related competences that make effective communication possible particularly in multicultural contexts relevant to migrant work environments.

In focusing here on communicative competence and employability, we are not seeking to reduce the debate about migrants and their labour market, let alone wider experiences to these issues. Our own interests are far wider than this, including both the broader lived experiences of such migrants and the political economy of skills development (McGrath 2004).

In looking at communicative competences and employability, it is important to avoid two traps: first, to see these as static and, second, to problematise and objectify the subjects of our research as being in deficit and needing assistance. The data that we present does show initial problems, and we believe that interventions could make some difference here. However, whilst some of our respondents have continued to struggle in making a successful transition to life and work in the UK, others have flourished having adapted and become increasingly competent in communicating their employability.

In the next section, we will explore some theoretical resources that allow us to unpick some of the complexities of the communicative competences of Zimbabwean migrants and the effects these have on their employability. After that, we will very briefly look at the nature of the sample and other issues of methodology before turning 
to the two key themes that emerge from the study, ending with a conclusion that points to the potential significance of this study and which outlines where we intend to take this research further.

\section{Theoretical Resources}

We mobilise two broad sets of theoretical resources in this paper. First, in keeping with much of the skilled migration literature, we draw upon political economy perspectives, specifically using the concepts of human capital and employability. Second, we draw upon sociolinguistic and related applied linguistic perspectives, examining the notion of communicative competence.

\section{Human Capital and Employability}

Human capital theory is highly contested (cf. Ashton and Green 1996; Boni and Walker 2013), and there is insufficient space here to explore the complexities of the debate. For the purpose of this paper, we will note that Becker's classic exposition (1964) has been drawn upon intensively in subsequent literature about migration, including notions of a 'war for talent' in which OECD countries' continued economic success is seen as being highly dependent on securing sufficient flows of skilled migrants from less developed countries (Michaels et al. 2001. This transnational view of human capital development means that language skills have increasingly been stressed as an important element of individuals' human capital (Grenier and Vaillancourt 1983; Chiswick and Miller 2007). Having command of a key language of business is argued to provide access to employment, enhance other job-related skills and increase productivity through effective oral and written communication. Indeed, the importance of more workers having a second language for business communications with major trading partners is a frequent refrain of business leaders in a range of countries.

Human capital theory is widely used to explain immigrants' labour employment outcomes (Sanders and Nee 1996; Bevelander and Veenman 2004). It appears that human capital is not always transferrable across national contexts (Friedberg 2000; Zeng and Xie 2004; Chiswick and Miller 2007; Zubin 2007). Part of this has to do with language, but it is generally argued that immigrants who speak the official destination language stand a better chance of more positive labour market outcomes (Chiswick and Miller 1995).

Employability too is a contested term (e.g. Gazier 1998; Peck and Theodore 2000; Brown and Hesketh 2004; McQuaid and Lindsay 2005; Clark and Zukas 2013; Li 2013). In its dominant, neoliberal form, it builds on earlier human capital accounts in responding to globalisation. It is essentially a three-act story. First, the decline of industrial production and the rise of a service (even knowledge)-based economy in the OECD countries necessitate a new form of preparation for the world-of-work. Second, the dominance of neoliberal ideology makes even parties formerly of the left abandon the welfare state and embrace education and work as the ways to end poverty and social exclusion. Third, the related notions of lifelong learning and boundaryless careers portray this new world as one of the exciting opportunities for those that embrace it. All of these factors are held to make a focus on an individual's ability to 
gain initial employment, maintain employment, move between roles within the same organisation, obtain new employment if required and (ideally) secure suitable and sufficiently fulfilling work; in other words, their employability is more important than the simple state of being employed (Hillage and Pollard 1998).

This dominant account emphasises individual agency as central to employability. Bauman (2007) argues that in contemporary advanced economies, it is the individuals' primary duty as citizens to be consumers. However, to be effective consumers, it requires production, hence, the revitalisation of old notions of the undeserving poor, those who do not work and those who do not deserve the rights and benefits of citizenship.

However, this atomistic view of employability has been countered by other traditions (especially from continental Europe, Gazier 1998) that see employability as necessarily being shaped by the interplay of structure and agency. McQuaid and Lindsay (2005), for instance, developed a detailed model of employability factors in which classic 'employability skills' were only one of ten elements alongside factors such as access to resources (including social capital), demand and (dis)enabling policies. Thus, we might expect that the employability of Zimbabwean graduates in England may be shaped by classic elements of human capital, including qualifications and language skills, conventional employability skills and wider factors such as social capital, immigration policies and economic structure. We must also acknowledge, and this is a limitation in the paper that an approach that focuses primarily on initial human capital of migrants runs the risk of downplaying their lifelong learning after migration. This is a point we will return to in the conclusion.

\section{Sociolinguistic Perspectives}

Communicative competence was introduced by Hymes as a challenge to Chomsky's notion of linguistic competence which he argued was too narrow to adequately account for contextualised human behaviour (Hymes 2001 [1972]). The concept has subsequently received a lot of attention in applied linguistics becoming the basis for communicative foreign language pedagogies. Its construct has been subject to constant evolution (Canale and Swain 1980; Canale 1983; Van Ek 1986; Pandharipande 1987; Bachman 1990; Celce-Murcia et al. 1995).

The notion of communicative competence includes a range of competencies generally recognised to include linguistic or grammatical (knowing how to use the grammar, syntax, phonology, vocabulary and orthography of a language), discourse (knowing how to interpret the larger context and create longer stretches of spoken or written language so that the parts create a coherent whole), actional (knowing how to convey and understand communicative intent), sociocultural (knowing how to use and respond to language appropriately, taking into account the social and cultural setting, topic and relationships between participants) and strategic (knowing how to recognise and repair breakdowns in communication, how to paraphrase to compensate for gaps in one's knowledge of the language and how to learn more about the language and in the context (Celce-Murcia et al. 1995).

The norms of appropriate language use defining the communicative competence second language learners of English were encouraged to acquire were those associated with mainly idealised native versions of American English and British English (Coperias Aguilar 2008; Sharifian 2013). This narrow view of communicative 
competence and approach to teaching did not take into account dialectal differences among native speakers of English themselves as well as the emerging varieties of English across the globe which have made native-speaker models of English language teaching irrelevant.

In the context of globalisation, there are a number of perspectives that are challenging the way we understand and use language. For example, current perspectives (e.g. Neo-Hymesian and applied Linguistic perspectives) observe that the increased mobility of English due to more current processes of globalisation has resulted in the development of more varieties of English wherever it occurs alongside other languages and as part of 'multilingual repertoires,' (Rampton 2006; Kramsch 2006, 2008; Pennycook 2007; Blommaert 2010, 2014; Canagarajah 2011, 2013; Sharifian 2013). Also noted is an increased non-native to non-native speaker use of English.

Further research on the increasing mobility of English highlights the limitations of linguistic competence in meaning making noting how language interacts with other features of meaning such as indexical, emblematic, aesthetic and others thereby suggesting taking into account 'infra-linguistic objects such as specific genres, registers, styles, accents, scripts and codes as well as the practices by means of which they are ordered as meaningful signs' (Blommaert 2014:3). Similarly, Kramsch (2006) notes that interlocutors in a multicultural context need to rely on much more than verbal clues and suggests a range of perceptual clues drawn from semiotic practices necessary for the creation and communication of meaning.

Consequently, the notion of 'proficiency' and its assessment are increasingly more complex in the postmodern communication era (Sharifian 2013) and, hence, the need for second language learners to develop a range of competences to supplement the traditional understanding of communicative competence. For example, to cope with the range of varieties and accents resulting from diversification of English, Canagarajah (2006: p. 233) proposes what he calls 'multidialectal competence' which would enable them to negotiate the different varieties for more effective communication.

Another competence, intercultural communication competence, which includes for example, a willingness to communicate with someone from another culture, appropriate culture (yours and the other person's) knowledge, appropriate communication skills in the target language, and sensitivity to cultural differences, is also considered critical for successful communication across cultures (Gudykunst and Kim 1997; Spencer-Oatey and Franklin 2009). Sharifian (2013: p. 5) has proposed adding to this what he calls 'metacultural competence' as a fundamental competence that enables interlocutors to negotiate cultural conceptualisations from multiple varieties of English.

For the ability to manipulate symbolic systems in particular multicultural contexts, Kramsch proposes what she calls symbolic competence. This competence is deemed necessary in circumstances where 'power, status and speaking rights are unequally distributed' (Kramsch 2006: p. 250) as in the case of the labour market.

Further, sociopragmatic competence has been suggested to help facilitate effective social interactions in multicultural workplaces which play a significant role in career progression (Clyne 1994; Holmes 2005; Holmes et al. 2009). International professionals find themselves unable to engage in small talk due to a lack of understanding of the dynamics of social interactions at the workplace (ibid). Research has shown that failure to engage in workplace small talk has a negative effect on migrant professionals' career achievement and social well-being (Cui 2012). 
This increasing complexity in communication highlights the need to adopt more dynamic approaches to studying communicative competence. While the large body of literature offering models for testing communicative competence provides important insights into the role of language in communicative competence (e.g. Brown and Abeywickrama 2010; Douglas 2010; Fulcher 2010; Carr 2011), the field could further benefit from the possibilities offered by the wider set of interlocking social science traditions that employ non-positivistic, non-hypothesis-based approaches to understanding social phenomena. This set of traditions includes diasporic and migration studies, sociolinguistics, education, development studies and others which provide diverse lenses for looking at the complexities of communication in the global context.

\section{English in Zimbabwe}

For black Zimbabweans, the history of English use dates back to the beginning of colonial rule in the 1890s. At independence in 1980, English was the first language of $2 \%$ of Zimbabweans but was used as a major language of communication amongst the African elite and as a second language in all regions of Zimbabwe for intra- and intergroup interaction, with some families being bilingual to the extent of using it interchangeably at home.

Bilingualism in Zimbabwe is best described as subtractive, which, according to Beardsmore (1986) occurs in contexts where the sociocultural attributes of one of the languages are denigrated in favour of those of the other, which typically has a more prestigious socioeconomically determined status. In Zimbabwe, colonial dynamics have resulted in English customs and language enjoying greater prestige over indigenous customs and languages, and English was accorded the status of official language for use in all formal domains such as education, administration and business. The prominence of English cannot however only be attributed to the colonial government but also to Africans who saw in English a way for their children to get an education that would provide them with employment opportunities (Summers 2002; Makoni and Makoni 2009). Not surprisingly, English fluency became a defining feature of a growing educated elite (Trudell 2005).

English continues to be widely used for administrative, technological, social and educational purposes. While the two major languages, Shona and Ndebele, are now used in some formal domains such as in Senate, English continues to dominate as the preeminent official language. An ' $\mathrm{O}$ ' Level in English is essential in order to be considered for further education, training or employment.

In terms of the variety of English that Zimbabweans speak and write, it has been noted that the idealised standard norm was introduced to school, but still, local varieties developed (Makoni and Makoni in press). For example, research has noted significant levels of Shona influence on English, Shona being the largest indigenous language and the one imbued with most political power. For example, Shona speakers have been observed to have problems at the phonological level, of distinguishing certain vowels sounds when speaking English because of the influence of Shona phonology on their spoken English (e.g. /e/, /æ/, / / are all realised as /e/ in words such as bed, bad and bird, respectively). Also, the stress and intonation patterns of Shona-influenced English are in some ways shaped by the intonation and accentual patterns of Shona giving it a distinctive accent. 
Some level of influence is also noted at the syntactic (e.g. use of the present progressive in place of the simple present as in 'I am not hearing what you are saying.' for I cannot hear), semantic (e.g. difficulty expressing different meanings in English where Shona might use one word. For example, the Shona word /kuda/ means /to love/, /to like/, /to want/, /to desire/), and discourse and rhetorical levels (e.g. high levels of what is seen in English as redundancy) (Thondhlana 2000).

In terms of graduates' level of proficiency, it should be noted however that the level of proficiency in English by indigenous Zimbabweans generally corresponds to the level of education. Therefore, the more educated a person is the more proficient they are in English. Zimbabwean graduates are therefore considered to possess the highest level of proficiency as they would have received far greater exposure to English within the education system. It should however be noted that this proficiency in English is basically institutionalised in that it is mostly English for study and business purposes and is used less for social interaction, a role reserved mostly for indigenous languages.

The status of English as a national official language entails that it is the language for much of official interaction, while indigenous languages take on the role of the language for much social interaction. English training therefore tends to focus on its official functions. As they progress within the university context where they are prepared for the workplace, English language training is focused more on communicating effectively within the academic setup and learning the English appropriate for the discipline or profession. During their university studies, for example at the University of Zimbabwe, they are required to pass English for Academic Purposes (EAP) as well as English for Specific Purposes (ESP) preparing them to communicate appropriately in their specific disciplines and also English for Occupational Purposes (EOP) to prepare them for interaction at the workplace. In addition, many employment organisations require further language training to equip them with more specific language skills for that organisation. So, it is not surprising that graduates and particularly those with some work experience come into the UK context with a strong occupational English foundation but not much English for social interactions.

It is reasonable to therefore conclude that Zimbabwean highly skilled migrants speak a variety marked by a high level of formal grammatical accuracy. For them, this RPbased variety is perceived to be a standard variety of British English which they expect to be widely spoken in Britain, an obvious mistaken assumption which they soon realise. Therefore, whilst highly skilled Zimbabweans manifest a high level of English proficiency/fluency, the notions of communicative and related competences hint at important further dimensions that impact upon their employability in England, as we shall explore shortly.

\section{The Study}

This article draws on data from what is intended to be the first phase of a larger study on the employability experiences of Zimbabwean graduates in different contexts. The data here comes from in-depth interviews with 20 highly skilled Zimbabwean graduates, educated in Zimbabwe but now employed in England. These interviews lasted an average of 1 hour. The interviews explored the employability challenges that they face 
in the English labour market and workplace and the strategies they use to negotiate and communicate employability. They come from a wide variety of academic and professional backgrounds. The sample consisted of 7 women and 13 men with ages ranging from 35 to 65, who migrated between 2000 and 2005. The identification of possible respondents was done by two of the research team, both highly skilled Zimbabwean migrants themselves and employed snowballing techniques. All participants were interviewed by both the Zimbabwean team members, and the encounters were recorded and transcribed. The data generated was anonymised and analysed thematically. The analysis was done jointly by the three team members, the third having been a highly skilled migrant to Zimbabwe. Each read the transcripts both with an autobiographical eye and through their own predominant disciplinary lenses - from sociolinguistics, the political economy of skills, and migration and diasporic studies. Individual interpretations of the data and identified codes were discussed in team meetings, and the paper then drafted and redrafted with different researchers taking the lead at different points in the iterative process.

These codes and the analysis in this paper reflect the use of a specific set of interdisciplinary lenses to view a specific small set of interviews. The stories told to us reflect the particularities of individual life histories, occupational backgrounds and moments of moving to England that make the data ungeneralisable. Equally, our analytical approach of trying to triangulate between three sets of disciplinary lenses produces a particular reading that highlights certain aspects of these individuals' stories but cannot generate a fully representative theorisation of their experiences in their totality, let alone theorise the employability experiences of Zimbabwean migrants or migrants more generally. Rather, our intention is to offer plausible stories about the ways that these particular individuals experienced and acted agentially in communicating their employability. It is in this presentation of issues, problems and experiences faced by our informants that the contribution of the paper lies.

\section{Communicating Employability 1: Formal Linguistic Competence Versus Communicative Competence}

Our study suggests that although Zimbabwean skilled migrants to England have high proficiency levels of formal English and thus appear initially strong in terms of human capital, employability and linguistic competence, on arrival, many manifest an understandable lack of awareness of the existence of varieties of English. Indeed, some continue to display an intolerance of and inability to deal with linguistic diversity. Unsurprisingly, they also manifest low levels of socioculturally appropriate language proficiency for the English workplace, at least initially. This impinges upon both their employability and their effectiveness and productivity in the workplace. Moreover, as sociolinguistic perspectives anticipate, Zimbabwean cultural norms, intertwined as they are with colonial and postcolonial effects, further undermine their initial communicative competences. As we shall show, these problems are quickly and relatively successfully overcome by some but remain pertinent for others.

These Zimbabwean graduates are very aware of the critical role played by the English language in the workplace. What is very striking is that they have a strong belief in their competence in this regard, as exemplified by the following quotation: 
Language is, uh, is, uh, I think it's the chief tool that can make you an outstanding fellow. If you can't communicate, you go to an interview, they're asking you and you don't even understand the question, you give them the wrong answer, you've failed the interview. I think it's the chief tool. But I come very good at language. So, if you want to succeed, if you want to be heard, if you want to be correct, you need to understand the language. It's a very important and useful tool (Former Education Officer)

Zimbabwean graduates interviewed see their English as being of a considerably high standard in comparison with British English varieties, regional varieties of neighbouring Southern African countries and varieties spoken in countries of other African regions. They continue to be proud of their grounding in received pronunciation and 'the Queen's English':

... there were some people here, I think they'd come from a place near Dudley, their, their tone is a little different from me, and for the first time I realised that the English that I speak, or I spoke then, because now I've been diluted, absorbed the accent, the English that I spoke, I realised, my boss later on told me, 'The English you're speaking is spoken in London and spoken by the Queen,' then that rang a bell that when I was still at high school, back in Zimbabwe, they told me, 'You should speak the English as spoken by the Queen.' (Electrical Engineer)

We know how to communicate better in English, although to be honest you find that when you come here you can't really understand what they're saying. It's probably because of the accent. And also the English in terms of, er, grammar is not how you've been taught in Zimbabwe. You find that in Zimbabwe English is more advanced if we speak, I think we are taught the Queen's English which is really very the high. There is a high standard of English in Zimbabwe than there is here (Environmentalist 1)

They contrast their English with the less proper forms of English they experience from those from British regions or from the rest of Africa:

if you go to Liverpool you can't even understand what they are saying, you know. If you go to Scotland you are completely lost, I mean. ... it's difficult to understand sometimes people from, from Ghana, Nigeria, the way they speak. But if you look at people from South Africa, Zimbabwe, Zambia, they're clear in the way they speak, and even, even the British will tell you, and even when you talk to somebody from Southern Africa you can understand them better than you do from somebody from Kenya or, because of the way they pronounce words. (Accountant)

This is not just that they struggle in understanding other accents and dialects but is based in a strong view that their own English is superior:

with the general or the below the line guys, I would put it that way, they were the ones you had difficulty communicating with because they speak this broken 
English which is standard in this country ... if you go to the illiterate people, the less learned people, that's where you have problems with communication because professionals communicate at a high standard English whereas the general person has got all these accents and different English languages, like patois English. (IT Engineer)

In this, they appear to internalise the power dynamics inherent in received pronunciation's status amongst World Englishes (Kachru 1981, a; Makalela 2007).

They believe that this level of formal language equips them well for highly skilled work:

Our English that we're trained was more of a business English kind of, not for you to be cracking jokes with, you don't know how to crack a joke, you don't know what's a joke. Er, so from that point of view, it is good in so far as it will make sure when you work with fellow professionals you fit in, um, if I meet my fellow engineers, we're talking exactly the same. ... But I think the content of our English language, by and large, everything written, and our written ability, made me to be able to deliver my job. When I speak they could hear me, there was no problems, so I could do all my presentation (Electrical Engineer)

However, this inability to 'crack a joke' is indicative of a sense of the two-edged nature of their English competence, which becomes apparent as we explore their narratives further. Thus, Zimbabwean graduates find it difficult to socialise in English, as it is perceived to be the language for more serious engagement. This reinforces the research of Chiwome and Thondhlana (1992), who found that English in Zimbabwe is 'venerated' in like manner to Latin and Sanskrit, a language of serious communication not to be used for jesting. Indeed, they noted that in lectures, academics would switch to Shona when giving anecdotes or telling jokes and then revert to English when giving more formal content. Similar observations have been made relating to the perceived critical role of English in providing access to a western-type education that would enable educated Africans to buy into an elite lifestyle (Summers 2002; Makoni and Makoni 2009).

The challenge for Zimbabwean graduates in England is that employees have to interact in the workplace both internally with their superiors, subordinates and workmates as well as, in some cases, members of the general public:

When I was doing my job I could deliver, but the moment I tried to have conversations, social conversations, I could not pick up what they were saying. There was one, this lady who comes somewhere from Dudley, that was really a challenge. She spoke English, but after my probation I had stars all over, but on communication/interaction, I didn't have a star on that one. I did pass the, after probation, I did get a pass, but one of the things that they needed me to work on was that, because understanding some of these accents particularly was a challenge. (Electrical Engineer)

Thus, the Zimbabwean graduates need to be able to demonstrate fluency across a range of registers and genres. Indeed, sociopragmatic competence has been found to be 
critical for rapport building and management within organisations and is important for negotiating membership within a particular professional or organisational community. As Holmes et al. (2009): p. 217) note:

Managing the synthesis between behaving in an appropriately professional way, while also constructing strong collegial relationships at work, requires considerable sociopragmatic proficiency.

Whilst some clearly have mastered this transition, it appears that for many, there are persistent employability challenges due to the nature of their language capital, which is stronger in the more technical, task-oriented communications required by their position within specific disciplines but which has tended to neglect the social dimension that is equally critical for negotiating and communicating employability in a broader sense.

We touched on the issue of understanding unfamiliar accents earlier, and this is worth returning to in greater detail as it clearly can impact negatively on employability. This is reflected powerfully in the following recollection of the problems one graduate faced in a job interview:

The first question they asked me, I had no clue what they were talking about! I just could not make sense of! (Psychologist)

In this case, this was overcome by a personal confidence (ascribed to counselling training) that led her to respond to this problem in an honest way that proved to be successful:

I just looked at the guy and said, 'Look, sorry, if I have to honestly and confidently answer your questions, I'll need to understand what you're asking me, so I would really appreciate it if you can try to be slow so that I understand what you are saying.' And I was actually surprised by myself, that I actually say that, and he was apologetic and said, 'Oh, you know, you've just come from Zimbabwe and I apologise, you know, we're very famous here for Geordie!' They laughed about it, and actually they slowed their pace, they, they actually started breaking down. And so, you know, again, those things matter, if, if you're being true to the interviewers and actually see that you're genuinely honest. (Psychologist)

However, others reflected on their continued lack of confidence in negotiating such language issues, which they saw as having postcolonial roots:

Yes, it's actually a question of identity, ... We always have this view that the white man is, is, is superior to us. (Accountant)

There's one thing that lack especially with Africans and I'll call it confidence. There is something still sitting at the back of their mind. We lack confidence because of our background, we have always looked at white people as superior ... And you can even see, even by the way 
we are sitting here we are still having a Zimbabwean community, we are failing to integrate (IT Engineer)

There was also a sense of shock for some in encountering other accents for the first time:

I now realise that the only thing that we didn't know when we were back home was there are different dialects of English. We thought everybody spoke English exactly the same in the UK ... other guys were from Scotland and other guys were from Ireland, they spoke English in a totally different way. So that became a challenge initially. (Electrical Engineer)

Many of the interviews gave a sense of both an initial and a continued intolerance of these other varieties that is apparently indicative of a lack of intercultural communication competence. Yet, as Millet (2003) notes,

Venturing into different cultures without adequate preparation can just be as dangerous as a ship manoeuvring icy waters without charts, hoping to be lucky enough to avoid hitting an iceberg (The cultural Iceberg, para. 3)

Over time, it appears that some have learned to develop stronger communicative, rather than just simple linguistic, competence in English:

There are lots of things: it's the way you communicate, it's the accent, it's, there's very little sometimes we can do about our accent, but perhaps maybe how we communicate verbally and so on, those are some of the skills maybe we may need to improve in, and perhaps how we even talk, just basic English and verbal skills and communication skills can make a difference, you know, and learning the, about the culture, how people communicate, because sometimes, you know, if I've come from a home where our communication is shouting, then I get to an environment where they don't shout, they talk calmly, so I've got to kind of match that. (Psychologist)

... if you want to socialise, you then need to speak other accents, the Geordie accent that comes from all over the place, the Yorkshire accent, so that's the other thing that you then realise, 'Mm, okay, you just need to pick that up.' (Electrical Engineer)

Such realisations are important to note. We are not arguing that Zimbabweans have an innate incapacity to communicate effectively in English work settings. Rather, they initially lack a broader communicative competence due to a combination of insufficient knowledge and strongly embedded sociocultural norms. However, what we see in some of these cases is a growing competence in the skills necessary to communicate their employability through managing less formalised linguistic interactions. Unfortunately, this is not a progression made by all, and communicative competence does appear to remain as a challenge for some. 


\section{Communicating Employability 2: Qualifications That Speak for Themselves Versus Narrativised Skills and Experiences}

Our analysis suggests that Zimbabwean highly skilled migrants to England face difficulties in communicating their employability in another significant way. The interviews, and our own personal reflections, suggest that Zimbabweans have a highly formalised view of human capital in which education leads to high status jobs and good wages. However, in England, so the interviews recount, this appears to run counter to another cultural approach. This lies in the shift towards employability and the need to narrativise one's self in the face of a more fluid labour market (Sennett 1999). As Brown and Hesketh (2004) show, employers are increasingly focused on how interviewees demonstrate their employability through a range of tests; the degree certificate serving as little more than a determinant of basic eligibility to be considered for employment.

The Zimbabwean internalisation of human capital theory fits well within broader accounts of education in Africa during the twentieth century. Foster's work on Ghana on either side of independence is seminal here. In this, he argued that the dominance of public sector employment both in the colonial service and in newly independent countries placed a very high premium on academic learning (Foster 1965a, b). Moreover, the trope of education as the way to advancement is deeply embedded in the Zimbabwean intellectual consciousness, through novels (e.g. Dangarembga 1988), biographies of the famous (e.g. on the Samkanges - Ranger 1995) and the classics of Pan-African thought (e.g. Du Bois 1903).

For the Zimbabwean highly skilled migrants in this study, the degree qualification automatically communicates that one is employable:

Back home you could get a job just by sending in a CV. The very moment they see that you have a Masters Degree, they're already head-over-heels for you (Researcher)

In Zimbabwe we are not required to provide a person specification as a basic $\mathrm{CV}$ that outlines your degree qualifications and related work experience will be adequate (Environmentalist 2)

In contrast, on arrival in the UK, graduates are confronted with a very different labour market context and a system that expects them to express the skills that make them employable. Not only is the degree (or higher degree in the case of the researcher above) less of a sign of distinction in a market with far higher levels of supply of such qualifications. More importantly, across a number of interviews, there is a sense that there was a communicative challenge with regard to employability for which they were unfitted. This is seen as beginning with the application process:

At times it's not necessarily about a degree, because here they value the skill, which is something very important, but when I came over here I had this idea that the very moment I say, 'I have a first degree. I have a Masters', it would do the trick, but it doesn't work. I tried it. Even the way I was writing my CV. Probably that's why I was being turned away, because at times I would just write, 'I've 
done this, and this, and this, and this', without emphasising the skills. What have I gained? What have I achieved? What am I bringing to the table?

Learning about that is something I think that has made me even get the jobs, because when I even go for a job, I don't even emphasise that I have a degree, but I talk about the skills that I have done. 'I've done research. I did it this way. We had this challenge. We had these issues. We came up with this', because I know that is what they want. (Researcher)

If you want to go for a job, what I will say as a hint to most people who want to go into their professions and not settle for less is that interviews here are to a set standard. If you Google you'll see exactly what's required in an interview. That's the only way you can sell yourself in this country (IT Engineer)

On getting past this first communicative hurdle, others found further barriers at the interview stage that went beyond the issue of accents explored above:

You know, in Zimbabwe maybe you go for an interview and you tell them all the academic things, and here the approach becomes different, you're selling yourself, you're not selling an academic thing. I can go in and tell them all about my degrees, but I've got to actually convince them that the degrees I've done, they are more than just knowledge I acquired, actually I'm applying that knowledge. ... Yeah, it's about what the graduates can offer. ...research about the company, what is it that they're lacking? So when you go there, tell them, 'This is what I'm going to do.' So I think it's about selling yourself more than anything here, [laughs] and that's my own experience. (Psychologist)

Language is therefore the key tool that enables the graduate to effectively communicate the level of competence and the nature of skills that he/she is bringing to the company, which seemingly present a challenge for some Zimbabweans:

You need to really sell yourself. You need to say what you have done and you need to say what you can offer. Because at the end of the day, you know, the managers, certainly in the UK, they're looking for what you bring to the table.... You need to be good with the language, and you need to be good with language so, you can explain. You need to really sell yourself. And when I say sell yourself I mean really sell, like, like, like really marketing yourself. Because some, some Zimbabweans they don't ... You need to say to them, 'I can actually do something here'. And some of them, like the guy at [graduate's current employer], I say to them, you know, 'When I come here I'll do this, that, I'll do that'. 'Oh, okay, so you can really do this?' 'Yes, I can do it'. 'Oh, is it? Okay'. So, you sell yourself and, you know (Civil Engineer)

Furthermore, in the world of multimodal recruitment assessment described by Brown and Hesketh (2004), some Zimbabwean graduates found themselves in the unfamiliar situation of having to demonstrate their skills by way of solving a given problem and/or giving a presentation: 
When they called me for an interview, I think they gave me a scenario of a research issue and they asked me to prepare a PowerPoint presentation. Yes and when I got at the interview, they also had another, some research data where they wanted somebody to say, 'Okay. Can you make sense of this data? How do you interpret it?' So you would go into a little room for forty-five minutes and begin to write like a mini-report. (Researcher)

Thus, it appears that one particular communication challenge that Zimbabwean graduates face in the English labour market relates to their lack of the sociopragmatic competence to express and evidence their skills and expertise in a way that is compatible with the extremely skills-based system of the host country. One possible factor here is that Zimbabweans come from a collectivist culture where they assume a common understanding of their capabilities as educated people within particular disciplines and specific work environments. So, for example, if one has a degree in the medical sciences, the assumptions are that other medical scientists and the related medical sciences employment companies will readily recognise that the graduate has the necessary skills. Thus, there would not be any need for the graduate to prove him/ herself, for example, through rigorous job application processes such as a tailor-made $\mathrm{CV}$, fit to job specification and skills-based assessment centres.

As with the first theme, we are suggesting that the apparent benefits accruing from the high levels of linguistic competence of Zimbabwean graduates are not enough to communicate their employability effectively in the new labour market context they experience in England. Again, in parallel with the first theme, we are not seeing this as insurmountable, however. Essentially, the Zimbabwean graduates need to acclimatise to the UK job market context in order to enhance their employability. This requires them to learn new communicative competencies that allow them to narrativise their education and work lives in appropriate ways. Though this is culturally alien, it can and is learned. Thus, the researcher from our last quotation continues by saying:

And because now I'd discovered that in the UK the focus is on skills, it's not on education. So I'd prepared myself thoroughly in that area. So I think that really helped me as well to get the job. (Researcher)

\section{Conclusions}

The literature on skilled migration is slowly coming to terms with the employability challenges faced by graduates in host economies, something that the popular 'war for talent' accounts have tended to underplay. Where language has been seen as an issue, it has typically been in terms of the linguistic deficits of migrants moving to countries in cases where they lack high levels of linguistic competence in the main language(s) of business and society. Relatively little attention has been paid to the experiences of the large numbers of highly skilled migrants from the African and Caribbean Commonwealth nations as pertains their linguistic competences. Educated largely in English-medium environments, it is widely perceived that such graduates will not experience language-based challenges to their employability. 
However, our initial study makes it clear that such challenges are real and profound. Our first theme shows that Zimbabwean highly skilled migrants to England initially tend to manifest relatively low levels of socioculturally appropriate language proficiency for the English workplace. These limitations are reinforced by cultural effects (some mediated by colonialism and postcolonialism) and impact negatively on both chances to gain employment and effective working once employed. Our second theme suggests that Zimbabwean skilled migrants to England face further difficulties in communicating their employability due to the dissonance between their highly formalised view of human capital and an English turn towards employability and the need to narrativise one's self in the face of a more fluid labour market.

Both themes point to a tendency towards excessive formalisation as a problem for Zimbabwean skilled migrants. This can be seen as having deep sociocultural roots that are typical of postcolonial mentalities, as well as being a rational response to the nature of African labour markets (at least in the colonial and postindependence eras, if not in the new era of African economic renaissance). However, it appears from the interviews that such mentalities can be unlearnt, although often painfully and over a relatively long period of time, in a new setting.

Exploring these patterns of learning to negotiate and communicate competence needs further unpacking that is beyond what is possible in a paper of this length. In subsequent papers, we intend to explore the messy pathways through which some of our respondents have negotiated successful careers in England, whilst others have remained stuck. We will also consider to what extent social and other capitals, for instance, spiritual capital (Grace 1995), may be explanatory in successes and failures.

The study is of a particular African diaspora at a particular moment in time and to a particular host country. It remains to be seen whether there is something particular about Zimbabweans and whether their experiences in other host countries, such as South Africa, are significantly different. A further limitation is that the study is about those who grew up in a distinct era of African educational and economic development that may now be coming to an end.

Nonetheless, the study does have something significant to say about the complexities of how migrants communicate employability and how this is shaped by their communicative competence in the language and culture of the countries in which they find themselves.

\section{References}

Ashton, D., \& Green, F. (1996). Education, training and the global economy. Cheltenham: Edward Elgar. Bachman, L. F. (1990). Fundamental considerations in language testing. Oxford: Oxford University Press. Bauman, Z. (2007). Consuming life. Cambridge: Polity.

Beardsmore, H. B. (1986). Bilingualism: basic principles (2nd ed.). Clevedon: Avon: Multilingual Matters. Becker, G. S. (1964). Human capital. New York: Columbia University Press.

Benson-Rea, M., \& Rawlinson, S. (2003). Highly skilled and business migrants: information processes and settlement outcomes. International Migration, 42, 59-79.

Bevelander, P., \& Veenman, J. (2004). Variation in perspective: the employment success of ethnic minority males in the Netherlands, 1988-2002. International Migration, 42, 36-64.

Blommaert, J. M. E. (2010). The sociolinguistics of globalization. Cambridge: Cambridge University Press.

Blommaert, J.M.E. (2014). "Sociolinguistics and English language studies." In Handbook of English language studies. C. Leung and B. Street (Eds.), Abingdon: Routledge, Taylor \& Francis Group. http://www. academia.edu/1416200/Sociolinguistics_and_English_Language_Studies 
Boni, A., \& Walker, M. (Eds.). (2013). Human development and capabilities. London: Routledge.

Brown, H. D., \& Abeywickrama, P. (2010). Language assessment: principles and classroom practices (2nd ed.). New York: Pearson Longman.

Brown, P., \& Hesketh, A. (2004). The mismanagement of talent. Oxford: University Press.

Canagarajah, A. S. (2006). Changing communicative needs, revised assessment objectives: testing English as an international language. Language Assessment Quarterly, 3, 229-242.

Canagarajah, A. S. (2011). Codemeshing in academic writing: identifying teachable strategies of translanguaging. The Modern Language Journal, 95, 401-417.

Canagarajah, A. S. (2013). "Skilled migration and development: portable communicative resources for transnational work." Multilingual Education, 3:8. http://www.multilingual-education.com/content/3/1/8

Canale, M. (1983). From communicative competence to communicative language pedagogy. In J. C. Richards \& R. W. Schmid (Eds.), Language and communication (pp. 2-27). London: Longman.

Canale, M., \& Swain, M. (1980). Theoretical bases of communicative approaches to second language teaching and testing. Applied Linguis, 1, 1-47.

Capps, R., McCabe, K. \& Fix, M. (2011) New streams: black African migration to the United States. Washington, DC: Migration Policy Institute. http://www.migrationpolicy.org/pubs/africanmigrationus.pdf

Carr, N. T. (2011). Designing and analyzing language tests. Oxford: Oxford University Press.

Celce-Murcia, M., Dörnyei, Z., \& Thurrell, S. (1995). Communicative competence: a pedagogically motivated model with content specifications. Issues in Applied Linguis, 6, 5-35.

Chiswick, B. R., \& Miller, P. W. (1995). The endogeneity between language and earnings: international analyses. Journal of Labor Economics, 13, 246-288.

Chiswick, B.R., \& Miller, P.W. (2007). "The international transferability of immigrants' human capital skills." IZA Discussion Papers 2670, Institute for the Study of Labor (IZA)

Chiswick, B. R., Lee, Y. L., \& Miller, P. W. (2006). Language skills and visa category. International Migration Review, 40, 419-450.

Chiwome, E., \& Thondhlana, J. (1992). "Sociolinguistics and education: a survey concerning attitudes on the teaching of Shona through the media of Shona and English." In Language and Society in Africa. Ed. R. K. Herbert. Cape Town, South Africa: Witwatersrand University Press. 247-263.

Clark, M., \& Zukas, M. (2013). A Bourdieusian approach to understanding employability: becoming a 'fish in water'. Journal of Vocational Education and Training, 65, 208-219.

Clyne, M. (1994). Intercultural communication at work: cultural values in discourse. Cambridge: Cambridge University Press.

Coperias Aguilar, M.-J. (2008). Dealing with intercultural communicative competence. In E. S. Alcon \& M. P. Safont Jorda (Eds.), Intercultural language use and language learning (pp. 59-78). Milton Keynes, England: Springer.

Cui, X. (2012). Problematic Chinese-Australian social interactions at work. University of Melbourne, Melbourne Graduate School of Education

Dangarembga, T. (1988). Nervous conditions. London: The Women's Press.

Douglas, D. (2010). Understanding language testing. London: Hodder Education.

Du Bois, W. (1903). “The talented tenth.”. In B. Washington, W. Du Bois, C. Chesnutt, W. Smith, H. Kealing, P. Dunbar, \& T. Fortune (Eds.), The Negro problem. New York: James Patt and Co.

Foster, P. (1965a). Education and social change in Ghana. Chicago: University of Chicago Press.

Foster, P. (1965b). "The vocational school fallacy in development planning.". In C. Anderson \& M. Bowman (Eds.), Education and economic development. Chicago: Aldine.

Friedberg, R. M. (2000). You can't take it with you? Immigrant assimilation and the portability of human capital. Journal of Labor Economics, 18, 221-251.

Fulcher, G. (2010). Practical language testing. London: Hodder Education.

Gazier, B. (1998). Employability: definitions and trends. In B. Gazier (Ed.), Employability: concepts and policies. Berlin: European Employment Observatory.

Grace, G. (1995). School leadership. London: Routledge.

Grenier, G., \& Vaillancourt, F. (1983). An economic perspective on learning a second language. Journal of Multilingual and Multicultural Development, 6, 471-483.

Gudykunst, W. B., \& Kim, Y. Y. (1997). Communicating with strangers: an approach to intercultural communication. New York: McGraw-Hill.

Harvey, W. S. (2008). British and Indian expatriate scientists finding jobs in Boston. Global Networks, 8, 453-473.

Hawthorne, L., \& Burrell, R. (1997). Immigrants and the professions in Australia. Melbourne: Monarsh University. 71.

Henderson, A., Trlin, A., \& Watts, N. (2001). "Squandered skills? The employment problems of skilled Chinese immigrants in New Zealand.”. In R. Starrs (Ed.), Asian nationalisms in an age of globalisation (pp. 106-123). Richmond, Surrey: Curzon Press. 
Hillage, J., \& Pollard, E. (1998). Employability: developing a framework for policy analysis. In Research Brief 85. London: Department for Education and Employment.

Holmes, J. (2005). When small talk is a big deal: sociolinguistic challenges in the workplace. In M. H. Long (Ed.), Second language needs analysis (pp. 344-372). Cambridge: Cambridge University Press.

Holmes, J., Riddiford, N., \& Lung, J. (2009). “Talk at work: interactional challenges for immigrants.”. In V. K. Bhatia, W. Cheng, \& B. Du-Babcock (Eds.), Language for professional communication: research, practice and training (pp. 215-234). Hong Kong, China: City University of Hong Kong.

Hymes, D. (2001). “On communicative competence.”. In A. Duranti (Ed.), Linguistic anthropology. A reader (pp. 55-73). Oxford: Blackwell Publishers.

Kachru, B. B. (1981). The pragmatics of non-native varieties of English. In L. Smith (Ed.), English for crosscultural communication (pp. 15-39). London: Macmillan.

Kramsch, C. (2006). From communicative competence to symbolic competence. Modern Language Journal, 90, 249-252.

Kramsch, C. (2008). Ecological perspectives on foreign language education. Language Teaching, 41, 389-408.

Li, Z. (2013). A critical account of employability construction through the eyes of Chinese postgraduate students in the UK. Journal of Education and Work, 26, 473-493.

Makalela, L. (2007). Nativization of English among Bantu language speakers in South Africa. Issues in Applied Linguis, 15, 129-147.

Makoni, S., \& Makoni, B. (2009). "English and education in Anglophone Africa: historical and current realities.”. In M. Wong \& S. Canagarajah (Eds.), Christian and critical English language educators in dialogue: pedagogical and ethical dilemmas (pp. 106-119). Routledge: Taylor and Francis.

Makoni, B., and Makoni, S. (in press). "English as a postcolonial language in Africa." In handbook of English as a foreign language. de Bot, K., K. Schrader, and D. Wolff. (Eds.) Routledge, Taylor, and Francis.

McGrath, S. A. (2004). Shifting understandings of skills in South Africa. Cape Town: HSRC Press

McQuaid, R. W., \& Lindsay, C. (2005). The concept of employability. Urban Studies, 42, 197-219

Michaels, E., Handfield-Jones, H., \& Axelrod, E. (2001). The war for talent. Cambridge, MA: Harvard Business Press.

Millet, J. (2003). What is culture. http://www.culturalsavvy.com/culture.htm

Negash, N. (2011). English language in Africa: an impediment or a contributor to development?". In H. Coleman (Ed.), Dreams and realities: developing countries and the English language. London: British Council. http://www.teachingenglish.org.uk/sites/teacheng/files/Z413\%20EDB\%20Section08.pdf.

Pandharipande, R. (1987). On nativization of English. World Englishes, 6, 149-158.

Peck, J., \& Theodore, N. (2000). "Beyond employability”. Cambridge Journal of Economics, 24, 729-749.

Pennycook, A. (2007). Global Englishes and transcultural flows. London: Routledge.

Rampton, B. (2006). Language in late modernity: interaction in an urban school. Cambridge: Cambridge University Press.

Ranger, T. (1995). Are we not also men? Oxford: James Currey.

Sanders, J. M., \& Nee, V. (1996). Immigrant self-employment: the family as social capital and the value of human capital. American Sociological Review, 61, 231-249.

Schellekens, P. (2001). English Language as a barrier to employment, training and education. London: DfEE.

Sennett, R. (1999). The corrosion of character. London: W.W. Norton.

Sharifian, F. (2013). "Globalisation and developing metacultural competence in learning English as an international language.” Multilingual Education, 3, 7. http://www.multilingual-education.com/content/3/1/7

Spencer-Oatey, H., \& Franklin, P. (2009). Intercultural interaction: a multidisciplinary approach to intercultural communication. New York: Palgrave Macmillan.

Summers, C. (2002). “Colonial lessons: Africans' education in Southern Rhodesia 1918-1940.” Oxford, UK: James Currey. Routledge Research Education in Anglophone Africa, 119

Thondhlana, J. (2000). Contrastive rhetoric in Shona and English argumentative essays. Harare: University of Zimbabwe Publications

Trudell, B. (2005). Language choice, education and community identity. International Journal for Academic Development, 25, 237-251.

Van Ek, J. A. (1986). "Objectives of foreign language learning.” Scope 1. Strasbourg: Council of Europe, Publications Section

Van Tubergen, F., \& Kalmijn, M. (2009). A dynamic approach to the determinants of immigrants language proficiency: the United States, 1980-2000. International Migration Review, 43, 519-543.

Zeng, Z., \& Xie, Y. (2004). Asian-Americans. Earnings disadvantage re-examined: the role of place of education. American Journal of Sociology, 109, 1075-1108.

Zubin, A. (2007). Geographical migration, psychological adjustment and reformation of professional identity. Globalisation, Societies and Education, 5, 239-255. 